\section{Epidemiologia, promoção da saúde e o paradoxo do risco*}

\section{Epidemiology, health promotion and the risk paradox}

\author{
José Ricardo de Carvalho Mesquita Ayres \\ Médico Sanitarista \\ Livre Docente do Departamento de Medicina Preventiva \\ Faculdade de Medicina \\ Universidade de São Paulo \\ Av. Dr. Arnaldo, 455 - $2^{\circ}$ andar \\ 01246-903 - São Paulo - SP \\ jrcayres@usp.br
}

* Apresentado como Painel no V Congresso Brasileiro de Epidemiologia. Curitiba, PR, Brasil. 23-27 de março de 2002.

\section{O Desafio Conceitual da Promoção da Saúde e o Paradoxo do Risco.}

Observa-se, em tempos recentes, em particular nos países latino-americanos, uma importante tendência de transitar, nos modelos de organização da assistência à saúde, da priorização quase absoluta de práticas centradas na doença, na assistência curativa, na intervenção medicamentosa, para outros que buscam orientar-se ativamente em direção à saúde, isto é, às práticas preventivas, educação em saúde e à busca da qualidade de vida, de um modo mais geral ${ }^{1}$.

No plano do fazer, isto é, das práticas de assistência institucionalizadas, essa ativa orientação pela idéia de saúde está bem representada pelas recentes propostas de vigilância da saúde ${ }^{2,3}$ e promoção da saúde $e^{4,5}$, que têm recebido uma vigorosa aceitação e importantes investimentos técnicos no meio sanitário brasileiro.

A vigilância da saúde, ampliando escopo e métodos da tradicional vigilância epidemiológica, ainda permanece mais estreitamente relacionada ao controle dos agravos como forma de cuidar da saúde, mas já realiza um deslocamento substantivo quando vincula esse controle a processos regionalizados e democratizados de definição de preocupações prioritárias e de suas correlatas estratégias de intervenção e monitoramento. Além disso, incorpora objetos de vigilância mais amplos que as antigas doenças de notificação compulsória, como as questões nutricionais, ambientais, a saúde mental, as relações entre saúde e trabalho ou a violência. De outro lado, busca também acompanhar não apenas agravos e riscos, mas a própria adesão a cuidados de saúde, como a adoção de medidas de autocuidado, a freqüência a consultas, a realização de screenings, entre outros.

As recentes propostas de promoção da saúde guardam estreitas afinidades com essa concepção ampliada de vigilância. Estão radicadas, em essência, na mesma compreensão do que seja a tarefa de assistir à saúde e, portanto, de seus objetos e estratégias. 
Contudo, aqui, ainda mais que na vigilância da saúde, há a noção de que a saúde não se define apenas pelo monitoramento e controle do que a pode ameaçar. Uma definição negativa de saúde parece limitada sob a ótica da promoção. A ampliação que esta postula aspira intervir não apenas naquilo que se deve evitar que aconteça para que se possa viver de forma saudável, mas quer estabelecer patamares que devem ser alcançados, em termos de aquisições positivas do ponto de vista físico, mental, emocional, cultural, ambiental, etc., para caracterizar uma boa qualidade de vida.

Um tal norte no plano do fazer, como se poderia supor, estabelece um importante desafio para o plano do saber, qual seja, uma conceituação positiva de saúde. Com efeito, se não se trata mais apenas de saber o que evitar, mas sim de reconhecer o que alcançar, as definições negativas de saúde, aquelas que a delimitam por intermédio do contraste com a presença de riscos e agravos, mostrar-se-ão limitadas e, em certas situações, até limitantes, para instruir novos modelos assistenciais. Construir uma referência objetiva sobre que atributos e condições devem receber a qualificação de saudáveis e, enquanto tal, se tornarem objetivos a serem perseguidos pelas práticas médico-sanitárias, é, portanto, um corolário da proposição técnica da promoção da saúde.

O presente trabalho consiste em uma reflexão preliminar, uma primeira aproximação teórico-filosófica a este desafio conceitual da promoção da saúde. Na forma de um ensaio crítico, pretende-se interrogar até que ponto, e de que modo, é possível criar e manejar conceitos positivos de saúde no âmbito do arsenal disciplinar atual da saúde coletiva, e muito em particular da epidemiologia. A questão central deste ensaio é, em síntese, a interrogação acerca das contribuições que a epidemiologia pode trazer para uma conceituação positiva de saúde. A tese que será examinada é a de que o paradigma do risco, dominante nesta ciência na atualidade, coloca a epidemiologia em uma situação paradoxal: nenhuma outra ciência biomédica tem tanta liberdade meto- dológica para tomar a saúde como objeto positivo de conhecimento quanto a epidemiologia e, ao mesmo tempo, poucas têm tão restritas possibilidades epistemológicas de validar esse conhecimento.

Para desenvolver esta tese buscar-se-á recuperar o processo de construção histórico-epistemológica da epidemiologia do risco. Essa crítica histórico-epistemológica fornecerá os elementos necessários para a compreensão do paradoxo do risco, permitindo identificar os desafios metodológicos, epistemológicos e filosóficos colocados pelo embasamento conceitual da promoção da saúde. Por fim, serão discutidas algumas alternativas de caminhos para responder a tais desafios.

\section{Formalização da Epidemiologia e Implicações para o Conhecimento em Saúde}

Para se proceder ao exame, ainda que sintético, da constituição da ciência epidemiológica, desde suas origens oitocentistas até a configuração do que está se chamando aqui de paradoxo do risco, é preciso apontar alguns de seus pressupostos e procedimentos conceituais. Não há qualquer pretensão acadêmica mais ambiciosa nessa proposição, mas tão somente a preocupação de evitar incompreensões limitantes para o debate aqui sugerido.

Em primeiro lugar, quando se faz referência à formalização da epidemiologia, já no título desta seção, está se assumindo, com Foucault ${ }^{6}$ e outros ${ }^{7,8}$, que o que caracteriza um saber científico é uma certa organização discursiva, onde a argumentação acerca da possibilidade de compartilhamento de uma dada crença acerca dos fatos se organiza na forma de uma relação de necessidade lógica entre premissas, argumentação e verificação. Com ajuda da experimentação, ou simplesmente apoiando-se na dedução lógica ou na matemática, a grande marca das ciências modernas é terem se constituído nesse modo de argumentar, em que a forma de se fazer perguntas sobre o mundo e a obtenção da convicção sobre a correção das res- 
postas dadas apóiam-se fundamentalmente nas implicações formais entre hipóteses e conclusões.

A formalização de um saber é, por conseguinte, um processo histórico e sócio-político de "depuração" de um discurso com pretensões de verdade, no sentido do estabelecimento e da legitimação de um conjunto auto-suficiente de correspondências necessárias entre seus elementos lingüísticos e as possibilidades de manifestação dos fenômenos.

Em segundo lugar, é preciso esclarecer que, pela razão mesma de ser fruto de um processo sócio-político, a definição do ponto a partir do qual se aceita a auto-suficiência argumentativa de um discurso formalizado e as correspondências que este estabelece entre linguagem e fenômenos, prestarse-ão sempre a uma interpretação crítica. A racionalidade dessas definições e correspondências, por ser originada de homens e mulheres e por ser a eles mesmos destinada ${ }^{9}$, permitirá sempre inquirir quanto aos valores e interesses, circunstâncias objetivas e perspectivas subjetivas que conformaram esses discursos formalizados ou, utilizando a terminologia de Habermas ${ }^{10}$, suas pretensões (e condições) de validade normativas, proposicionais e expressivas, respectivamente.

Foi a partir da interrogação acerca dessas pretensões/condições de validação social do discurso epidemiológico que se elaborou a recuperação histórica e a compreensão do desenvolvimento da ciência epidemiológica, já apresentados em outro trabalho ${ }^{11}$ e que serão abaixo retomados. Será examinada, nesse sentido, a formalização do discurso epidemiológico nos moldes do discurso do risco nas diferentes etapas de seu desenvolvimento, até a sua configuração atual. É claro que os propósitos deste ensaio impõem a necessidade de uma sistematização bastante sintética desse processo. Isto certamente emprestará à discussão um tom algo esquemático, um tanto inevitável, mas nem por isso infenso à necessária vigilância crítica.
Epidemiologia da Constituição (18721929)

Os primeiros traços de particularidade que permitem identificar o caráter discursivo próprio da epidemiologia entre os saberes da saúde podem ser sinteticamente descritos pelo conjunto articulado de três características pelas quais este discurso científico se validou socialmente: o controle técnico dos agravos à saúde como horizonte normativo; o comportamento coletivo dos fenômenos patológicos como a base sobre as quais a verdade das proposições epidemiológicas se apoiavam; e a variação quantitativa como a linguagem que mais autenticamente expressava a possibilidade de se apreender e intervir sobre tais fenômenos coletivos e o seu controle técnico. O período, o ambiente e os personagens que descrevem o processo de formalização da epidemiologia serão descritos, portanto, como a crônica dessa tríade discursiva básica: "controle técnico - comportamento coletivo - variação quantitativa".

Os primeiros saberes com pretensões de cientificidade de traços modernos voltados para a apreensão dos fenômenos coletivos de saúde podem ser localizados na higiene social do período revolucionário, perfeitamente bem representada pela obra de Villermé12 ${ }^{2}$. Contudo, ainda não se podia vislumbrar ali uma busca de relações minimamente estabilizadas em torno da tríade discursiva epidemiológica. Embora o "comportamento coletivo" dos fenômenos de saúde já fosse o elemento nuclear da sua identidade epistemológica, o predomínio das teorias miasmáticas nas formulações teóricas desta higiene - pela autonomia que conferia às "entidades patológicas" - denuncia a inadequação de considerarmos a "variação quantitativa" como o núcleo definidor da sua expressão objetiva. A referência a um comportamento indesejável, ou patológico, por meio da noção de variação quantitativa pressupõe um tratamento analítico de um mesmo "ente", isto é, a distinção de diferentes estados de um mesmo aspecto ou condição tomada como base para a avaliação objeti$\mathrm{va}^{13}$. Esse princípio de continuidade qualita- 
tiva entre o normal e o patológico é estranho à descontinuidade que a higiene sócionaturalista estabelecia entre uma existência saudável e existências doentias ${ }^{14,15}$. Há que se considerar ainda que a idéia de controle também não é adequadamente representativa do horizonte normativo da higiene social. Seja nas feições reformistas de Villermé, seja nas posições mais radicalmente revolucionárias dos higienistas saint-simonistas, a idéia de transformação social, ainda não qualificada na direção mais restrita de controle técnico, era ainda dominante.

Já em Snow, na Inglaterra vitoriana, encontra-se nitidamente conformado este eixo triádico, e é por isso que seu trabalho sobre o cólera muito justamente ostenta o título de fundador, embora o trabalho de Snow não tenha sido sempre paradigmático da epidemiologia ${ }^{16}$. Na conformação do discurso epidemiológico moderno há uma espécie de interregno, quando as teorias microbianas passam a responder quase exclusivamente pelos comportamentos epidêmicos ${ }^{17}$. No final do século XIX e início do XX, os "caminhos do germe" tornam-se socialmente mais eloqüentes que a epidemiologia para falar de comportamento coletivo das doenças e de seu controle técnico.

Mas se a epidemiologia não desapareceu sob a avassaladora hegemonia do discurso bacteriológico, se resistiu quase clandestinamente até experimentar o renascimento dos anos 20 e 30 deste século, é porque houve, efetivamente, uma região da experiência, ainda que de menor transcendência social, que não encontrou expressão no discurso bacteriológico. Foi preciso que se passasse o tempo de uma geração para que, sob o impulso de novas exigências de validação, possibilitadas inclusive pelo discurso bacteriológico, a particularidade discursiva da epidemiologia voltasse a ganhar visibilidade e força social.

A Escola de Higiene e Saúde Pública da Universidade Johns Hopkins (EHSP) é a mais perfeita expressão desse movimento. Nascida em 1916 nos Estados Unidos, a escola representou, no campo da saúde, uma ampla onda de reformas que sofreu o ensino uni- versitário norte-americano com vistas à sua modernização ${ }^{18}$. Financiada basicamente pela Fundação Rockfeller, essa reforma visava substituir o perfil elitista e filosóficohumanista predominante nas universidades do país por um ensino pragmático, voltado para o desenvolvimento tecnológico exigido pela radical guinada industrial do país. William Welch, quando montou a estrutura e o corpo docente da EHSP, tinha como projeto exatamente dotar a saúde pública de um conjunto de conhecimentos e técnicas que fizessem do sentido humanitarista e moralreligioso que impregnava práticas e concepções da "velha saúde pública" norte-americana coisa do passado. Welch encontrou na Alemanha, no Instituto de Higiene, de Pettenkofer, um modelo para a escola que veio a fundar nos Estados Unidos. Herdeira de uma grande tradição nas práticas sanitárias, a versão pettenkoferiana tinha um traço característico, extremamente interessante, em particular para os padrões sócio-culturais anglo-saxônicos e norte-americanos: a vocação experimental/laboratorial de sua filosofia científica e corpo doutrinário. Com efeito, nem o sentido sócio-reformista das formulações mais expressivas da higiene francesa, nem o caráter mais burocráticoestatizante da higiene inglesa, outras grandes "potências científicas" da época, estavam tão afinados com o projeto de modernização norte-americano.

Quando Pettenkofer, como uma espécie de Claude Bernard da saúde pública, propõe tratar as questões sócio-sanitárias, inclusive as questões de cunho econômico, como uma "macrofisiologia", buscando mecanismos favoráveis e desfavoráveis à saúde dos indivíduos e comunidades através dos cânones e procedimentos da ciência experimental, nasce o embrião de uma prática que, como o próprio Pettenkofer chegou a intuir ${ }^{19}$, só num ambiente de ascetismo laico tal qual criado pelo puritanismo norteamericano teria condições plenas de frutificar.

Riqueza material, progresso técnico, condições sócio-políticas internas favoráveis, poder internacional, puritanismo, o 
pragmatismo de James e Dewey, a ampla penetração do darwinismo... há uma série de aspectos articulados que permitem ver no ambiente sócio-político e científico-filosófico dos Estados Unidos do início do século condições de validade amplamente favoráveis ao argumento do controle técnico como sentido normativo fundamental para uma saúde pública "modernizada".

Welch foi buscar em Pettenkofer uma linguagem da economia funcional vital. $\mathrm{O}$ comportamento coletivo das doenças é aqui expressão das condições imediatamente constitutivas da interação de organismos humanos entre si, com organismos não-humanos e elementos externos não-orgânicos em um dado meio e por força desse meio. $\mathrm{O}$ comportamento epidêmico revela não apenas o encontro entre um germe e populações humanas, mas a resultante desse encontro na economia das funções vitais, individuais e coletivas. Tem-se, assim, que as características objetivas do fenômeno epidêmico passam a ser constatadas com o intermédio da distribuição dos casos, descrita segundo critérios analíticos de lugare tempo. Descrever os casos conforme esses critérios é imediatamente atestar a identidade das interações entre meio e organismos, expondo as características constitucionais de ambos. Era assim que se podia assumir, por exemplo, que para uma dada cidade a medida sanitária mais favorável à economia vital era o esgotamento sanitário, para outra o arejamento da moradia, para uma terceira cuidados nutricionais, ou, o que é mais comum na realidade de todas elas, afirmava Pettenkofer, um conjunto de medidas sanitárias capazes de atingir o mais amplamente possível as diversas interações desfavoráveis à vida.

O princípio de continuidade entre os estados de saúde e doença já se coloca aqui claramente, impondo o desafio ilimitado, e ilimitável, de otimização funcional, isto é, o ideal de um progressivo e contingente controle das "disfunções", visando a disposição mais produtiva da economia orgânico-social. O comportamento coletivo dos agravos fornece, por sua vez, uma segura base de positividade para os juízos de fato requeridos para esse controle. Ele permite uma "verificabilidade" potencialmente universal das relações funcionais examinadas, seja pela observação cuidadosa da posição relativa dos fenômenos estudados na economia sanitária, seja pelo cotejamento dessa economia com seus substratos fisico-químicos.

Ainda que na maior parte de suas proposições teóricas Pettenkofer tenha sido superado já no final do século XIX, sua obstinada defesa da especificidade e interesse da síntese que uma higiene científica devia buscar deu visibilidade ao caráter particular e transcendente de uma fenomenologia propriamente epidemiológica; foi permitindo à epidemiologia a construção de uma identidade científica e o alcance de uma mais clara e nova importância no início do século XX.

O termo risco começa a surgir no jargão epidemiológico ainda em plena fase da epidemiologia da constituição, em torno dos anos 20. À proporção que o conceito de "meio externo", relacionado a uma perspectiva mais teorética e ontológica acerca das "constituições” desfavoráveis à saúde, vai se rarefazendo conceitualmente, o risco vai se adensando, configurando uma perspectiva mais tecnicista e pragmática de tratar dos mesmos fenômenos. À medida em que o meio vai sendo marginalizado na estrutura argumentativa da epidemiologia, o risco vai definindo a sua centralidade até assumir, numa nova configuração discursiva, um papel definidor da perspectiva analítica mais característica da ciência epidemiológica.

\section{Epidemiologia da exposição (1930-1944)}

O final da década de 20 e início da década de 30 foi repleta de acontecimentos de enorme significado para a compreensão do modo como evoluíram as condições de validação social do discurso epidemiológico. Destaque-se, nesse sentido, de um lado a Grande Depressão do final da década, e de outro o espantoso desenvolvimento científico e tecnológico das ciências de um modo geral e em particular das ciências biomédicas.

Os enormes progressos tecno-científicos 
da área biomédica, especialmente os progressos da bacteriologia e a emergência da imunologia, levaram a que toda a busca de conhecimento acerca das forças favoráveis ou desfavoráveis à economia vital viesse a se deslocar dos estudos populacionais de base mais descritiva em direção a procedimentos mais e mais analíticos e relacionados com as investigações biomédicas. À saúde pública e à epidemiologia abriu-se um espaço sem precedentes, mas ao mesmo tempo se lhes foi exigido, mais radicalmente do que nunca, o diálogo com os conceitos e métodos das ciências que se ocupavam da economia vital no plano dos eventos fisiopatológicos do organismo humano. Para isso, foi vital a contribuição de um epidemiologista inglês bastante polêmico, mas muito respeitado por seus contemporâneos ingleses: Sir William Heaton Hamer.

Espécie de professor emérito de toda a primeira geração de epidemiologistas da London School, Hamer forneceu, ainda dentro dos marcos da epidemiologia da constituição, as possibilidades de sua superação rumo à epidemiologia da exposição. Hamer se notabilizou por duas contribuições verdadeiramente revolucionárias na discursividade epidemiológica. Uma delas é a retomada da preocupação com a formulação matemática de curvas epidêmicas, empreendimento inaugurado por Farr ${ }^{66}$ anos antes. Motivado por uma questão central na epidemiologia da constituição, a compreensão das razões pelas quais emergem e declinam espontaneamente as epidemias, Hamer construiu em 1906 a curva epidêmica do sarampo $^{20}$.

Hamer desenvolveu a expressão matemática do sarampo tendo por base a sua "teoria mecânica de números e densidade". Nessa teoria, os elementos constitucionais que determinavam o caráter persistente de uma doença e, ao mesmo tempo, sua remissão periódica, não necessitavam de nenhum elemento transcendental para sua explicação, tal como os miasmas, dominantes nas explicações da epidemiologia da constituição. Por outro lado, Hamer tampouco admitia, como o faziam os bacteriologistas, que a causa suficiente para o ir e vir das epidemias fosse conseqüência imediata da infectividade do agente. Ao invés disso, Hamer demonstrava que o comportamento epidêmico podia ser entendido, e formalizado matematicamente, como uma dinâmica dos contactos infectantes.

O declínio de uma epidemia acontecia, defendia Hamer, graças à "barreira mecânica" representada pelo processo de progressiva saturação do meio de disseminação da doença pelos "insuscetíveis", acumulados à proporção em que a epidemia progredia. Do mesmo modo, conforme essa barreira ia permitindo um novo acúmulo de suscetíveis, iam sendo criadas condições de contato favoráveis à nova explosão epidêmica da doença.

Embora Hamer tenha construído seu raciocínio ainda muito influenciado por conceitos e concepções da epidemiologia da constituição, esse epidemiologista fornece uma base bastante interessante para a sua sucedânea, a epidemiologia da exposição. Isto porque, por um lado, abriu um importante espaço para a quantificação, o que viria a ter enorme importância na década de 30 , após os significativos avanços que a estatística alcançou na década de 20. Por outro lado, o equacionamento dos diversos fatores envolvidos nos fenômenos epidêmicos e a elaboração de seus potenciais desdobramentos em função de suas relações matemáticas, confere aos fenômenos epidêmicos possibilidades de manipulação e preditibilidade extremamente interessantes para o ambiente pragmatista que passava a dominar a cena da época.

Sabe-se que a principal preocupação de Hamer quando formulou sua "lei da ação de massas" era distinguir e legitimar o discurso epidemiológico sobre as epidemias: a bacteriologia falava a respeito dos agentes, e a epidemiologia deveria falar da dinâmica de sua distribuição populacional, defendia ele. Sua motivação primordial era arrancar a explicação causal sobre os fenômenos epidêmicos do domínio exclusivo da bacteriologia, demonstrar a particularidade dos processos de que tratava a epidemiologia, aos 
quais chamava, parafraseando Sydenham, de constituições epidêmicas. Porém, conforme corria o século $\mathrm{XX}$, as exigências de validação dos discursos científicos se afastavam da preocupação com o sentido ontológico que inspirava o conceito de constituição epidêmica e valorizavam apenas o que fosse passível de formalização e aplicação pragmática.

Por isso, as "massas" estudadas por Hamer passaram a ser caracterizadas como pessoas sob ameaça, populações em risco. A "ação" em questão passou a designar especificamente a exposição a infecções. A "lei da ação de massas" reformulou-se, então, como "risco representado por exposição". O objeto epidemiológico passou a ser delimitado como uma relação entre infectados/ suscetíveis, que se define como oportunidade de exposição ao agente causal de uma doença. Eis a epidemiologia da exposição; eis a base epistemológica para a formalização do conceito de risco.

A partir desta base epistemológica, passou-se a buscar reconhecer o que um risco populacional dado permitia inferir sobre as condições de exposição a que esta população estava ou estivera submetida.

Wade Hampton Frost é o nome paradigmático desse processo. Frost deu ao sentido proposicional mais genérico da epidemiologia da exposição uma sólida estruturação, consolidando um caminho seguro para a formalização e particularização do discurso epidemiológico sobre os fenômenos de saúde e colocando-o em estreita relação com as ciências biomédicas. Foi Frost quem introduziu o elemento estocástico* nas curvas epidêmicas, possibilitando com isso uma extraordinária diversificação dos objetos de investigação dessa ciência e uma impactante ampliação da aplicabilidade de seus conhecimentos.

"Condições que afetam a freqüência do contacto entre microorganismo específico e população de hospedeiros são obviamente objeto de múltiplas variações, relaciona- das a mudanças de hábito ou meio ambiente", dizia. "Onde conhecemos o meio pelo qual uma infecção particular se espalha nós podemos freqüentemente concluir com alguma segurança que uma determinada mudança de hábito ou no meio tenderá a aumentar ou diminuir as oportunidades de transferência do agente infeccioso específico (aglomeração, poluição da água), e encontramos abundantes evidências de que o aumento da exposição está associado na natureza ao aumento na incidência da infecção". Contudo, considerava Frost, como na maior parte das vezes não se dispõe dessas informações, as exposições, sob condições naturais, isto é, não laboratoriais, "só podem ser expressas como a probabilidade de que um indivíduo qualquer na população sob risco vá receber num dado período um número dado de microorganismos específi$\cos ^{\prime 21}$.

Assim, Frost formula a problemática epidemiológica nos termos do risco, liberando o raciocínio epidemiológico de qualquer compromisso com a exploração exaustiva das condições constitucionais das epidemias, que relacionariam a doença no indivíduo ao conjunto das condições sanitárias examinadas. Com o controle estatístico das incertezas, o conceito de risco encontra-se livre para delimitar um, e qualquer um, dos aspectos de interesse pragmático. Além disso, a suscetibilidade representada pelo risco não precisa mais ficar restrita à chance de ser infectado, mas também de adoecer, de não adoecer, de adoecer de modos diferentes, de morrer, etc.

Com a maior precisão na formulação de suas questões e na credibilidade de suas respostas, a aplicação e o prestígio científico do conhecimento epidemiológico avançaram rapidamente; o uso dos núcleos familiares e outros espaços mais restritos de sociabilidade, como escolas, creches, ambientes de trabalho, deram aos desenhos de estudo, por sua vez, uma agilidade operacional inédita nas investigações epidemiológicas, contribu-

* Do grego stokós (conjectura) A palavra indica que nos colocamos do ponto de vista da probabilidade. Uma ligação estocástica entre dois conjuntos $\mathrm{E}$ e $\mathrm{F}$ associa aos elementos de $\mathrm{E}$ não um elemento determinado de $\mathrm{F}$, mas um elemento de que se sabe apenas pertencer a um subconjunto determinado de F (Lalande, A. Vocabulário Técnico e Crítico da Filosofia. São Paulo: Martins Fontes; 1993: 1259). 
indo para um rápido e diversificado acúmulo de informações teóricas e metodológicas. Os métodos estatísticos, que desde as publicações de Fisher, a partir da segunda metade dos anos vinte, disseminavam-se amplamente entre os epidemiologistas, são também responsáveis pelo aumento da precisão não só da formulação das perguntas, mas também das respostas trazidas pelos estudos. Tudo isso foi levando o risco a se difundir, amadurecer e aglutinar a discursividade epidemiológica em um sentido que aponta para a constituição de um verdadeiro paradigma científico.

É esta necessidade argumentativa, controlada em termos probabilísticos, que mais e mais vai dando o sentido de legitimidade a um estudo epidemiológico. Liberado pelo raciocínio analítico abstrato e pelo elemento estocástico de seus compromissos com os contextos ontológicos, constitucionais, o risco é cada vez menos conteúdo e cada vez mais raciocínio, forma de estabelecer nexos causais. A epidemiologia achara finalmente uma forma necessária e própria de argumentar demonstrativamente, podendo perfilarse junto aos discursos de natureza científica.

\section{Epidemiologia do Risco (1945 aos dias atuais)}

Em 1959, o epidemiologista Brian MacMahon escreve para o Harvard Public Health Alumni Bulletin um artigo em que traça o perfil do Departamento de Epidemiologia da Escola de Saúde Pública de Harvard, e no qual fica clara uma nova e decisiva inflexão que, conduzida pelo conceito de risco, caracterizará a epidemiologia contemporânea. Diz ele: "As áreas de ênfase em todas as disciplinas científicas mudam de tempos em tempos, à proporção que descobertas promissoras são feitas em campos previamente estéreis e à proporção que as necessidades metodológicas relativas a um certo objeto passam de uma disciplina a outra. A epidemiologia não é exceção neste aspecto e está, com efeito, passando por um desses momentos de transição no presente. Na última metade do século, o objeto pre- dominante da epidemiologia foram as doenças infecciosas. Grandes progressos foram feitos no controle dessas afecções, embora elas permaneçam sendo o maior problema de saúde da maioria da população mundial, e a ameaça de grandes epidemias, mesmo no Mundo Ocidental, não esteja de modo algum afastada. A recente mudança de ênfase na epidemiologia é atribuída com freqüência à importância decrescente das doenças infecciosas no Oeste. Essa, contudo, é apenas uma explicação parcial. Essa tendência deve ser atribuída, ao menos em parte, às limitações dos próprios métodos da epidemiologia. A epidemiologia é primordialmente uma disciplina observacional. Observações com base na ocorrência natural da doença levam à formulação de hipóteses relativas a agentes causais específicos. O teste dessas hipóteses depende em parte de observações posteriores, mas em grande medida depende do experimento, freqüentemente de natureza laboratorial. Por exemplo, estudos observacionais conduzem à descoberta original dos agentes infecciosos, mas o entendimento e controle das doenças infecciosas dependem cada vez mais das técnicas laboratoriais da microbiologia, e cada vez menos da observação dos padrões epidêmicos das doenças"’2.

Ficam claras, no excerto acima, as novas exigências que se colocam para a epidemiologia do risco. MacMahon é cristalino na sua percepção de que o que se impõe não é só mudar o que se estuda, mas o modo e $o$ significado do que se estuda. E é evidente, nesse sentido, a pressão exercida na direção da especialização e sofisticação tecno-material da apreensão e intervenção em patologias específicas. A argumentação de MacMahon também deixa clara a subordinação epistemológica da epidemiologia às ciências biomédicas de base clínico-laboratorial, assim como permite perceber a relevância que tem essa característica do desenvolvimento epistemológico da epidemiologia na compreensão da sua inflexão no pós-Guerra.

Prosseguindo, afirma ainda MacMahon: "Tem havido, dessa forma, uma tendência 
na epidemiologia a deixar as doenças infecciosas para o microbiologista (ou para o epidemiologista adestrado em microbiologia) e a tratar principalmente das doenças crônicas não-transmissíveis, para as quais os métodos observacionais ainda não foram completamente explorados. Através do estudo das circunstâncias sob as quais essas doenças experimentam uma prevalência incomum, espera-se identificar áreas nas quais o trabalho experimental laboratorial possa se concentrar para a identificação dos agentes causais específicos.

O excerto acima permite perceber uma ênfase maior na dimensão especulativa do conhecimento epidemiológico em relação à compreensão da epidemiologia da exposição com respeito às suas vocações. Para esta última, a epidemiologia era muito mais uma disciplina analítica, ocupada não tanto com a etiologia da doença quanto com as condições de sua manifestação epidêmica. Na epidemiologia do risco, da qual MacMahon se faz um dos principais porta-vozes, não só cabe à epidemiologia a especulação causal como esta constitui mesmo sua razão de ser no conjunto das investigações biomédicas. Por outro lado, é patente para MacMahon que esta disciplina não pode pretender afirmar, senão sugerir, os vínculos causais que as ciências biomédicas duras devem definitivamente estabelecer.

Uma das mais marcantes conseqüências da inflexão experimentada pela epidemiologia do pós-guerra é essa "rarefação teórica" do seu discurso, isto é, uma deliberada restrição das pretensões de validade proposicional de suas construções objetivas. De fato, quando as pretensões objetivadoras da epidemiologia assumiram radicalmente sua dependência de uma positividade alheia à sua própria esfera discursiva, confiada às "ciências experimentais laboratoriais", a preocupação com a validade proposicional dos enunciados epidemiológicos limitou-se, concomitantemente, ao alcance formal de seus proferimentos. A universalidade a que passava a aspirar a epidemiologia do risco restringia-se, assim, à construção e verificação do caráter de necessidade formal das associações estabelecidas entre os eventos empíricos estudados.

Na primeira epidemiologia inglesa, tal como realizada por Farr, Ross, Brownlee e Hamer, especialmente, as relações de necessidade que se buscava estabelecer eram relativas a um certo campo de verdades sobre as quais um discurso constatativo se detinha. O que a epidemiologia tinha a dizer dos fenômenos de saúde era algo sobre o qual somente ela se propunha a falar e em relação ao qual somente a ela caberia construir e avalizar critérios de validação. As variações pelas quais o comportamento epidêmico era traduzido dependiam da natureza substantivamente coletiva do campo de objetividade em questão e a verdade dos enunciados que a epidemiologia buscava estabelecer era compreendida como um desdobramento intrínseco do mesmo, as depois chamadas "leis da ação de massas".

Com Frost inicia-se já um processo de subordinação epistemológica, mas em um grau ainda comparativamente elevado de autonomia em relação à epidemiologia do risco, pois se a consistência biológica era para ele uma exigência inequívoca para o conhecimento epidemiológico, essa busca de consistência estava mais vinculada à noção de unidade do conhecimento científico do que a uma hierarquização da "confiabilidade" das diversas ciências. Frost afirmava a identidade singular do objeto epidemiológico nos "massphenomena” e julgava imprescindível que os achados empíricos da epidemiologia fossem interpretados em um conjunto de referências apropriadas e particulares, em uma "filosofia consistente" ${ }^{23}$. Em Frost, e na epidemiologia da exposição de um modo geral, a noção de "epidemicidade", ou de "dispersabilidade", ou mesmo de "infectividade aparente”, eram ainda expressões de uma fundamentação estreitamente dependente dos fenômenos estudados e não do modo de conhecer esses fenômenos, como vem acontecer na epidemiologia do risco.

É evidente, nesse sentido, a diferença no modo como Frost e MacMahon situam o relacionamento do conhecimento epidemiológico com as ciências biomédicas "duras". 
No primeiro elas são testemunhas, no segundo juizes; em Frost, essas ciências são "parceiras" mais experientes na grande travessia "da ciência" para o "conhecimento pleno"; em MacMahon, são a fonte segura de objetividade para um saber empreendedor, que estabelece finalidades determinadas e quer controlar seus alcances em relação às mesmas. A preocupação com a validade proposicional dos enunciados epidemiológicos limitou-se, desse modo, ao alcance formal de seus proferimentos. A epidemiologia do risco restringiu-se à construção e verificação de associações probabilísticas entre eventos empíricos de interesse no campo da saúde.

Um dos mais inequívocos sinais desta inflexão é a ausência quase absoluta de discussões ou sistematizações teóricas relevantes acerca desta ciência ou de seu objeto nesse período.

Na clássica definição de MacMahon para a epidemiologia - "o estudo da distribuição da doença e a busca dos determinantes da distribuição encontrada" ${ }^{24}$ - encontramos o mesmo acento instrumental, assinalado pelo uso da expressão "o estudo de..." que, conforme aponta David Lilienfeld ${ }^{25}$, veio substituir, a partir da década de 50, a expressão "a ciência da ..." nas autodefinições da epidemiologia. Além disso, o elemento nuclear da definição é a "doença”, sem qualquer adjetivação ou circunstanciamento, indício da fonte última (e primeira) da positividade dos enunciados epidemiológicos: as ciências biomédicas laboratoriais. Ao final da sua discussão sobre as diversas definições da epidemiologia, Lilienfeld sintetiza naquela que ele próprio formula esta dependência epistemológica e a rarefação teórica da epidemiologia, conseguindo em sua proposição ser ainda mais "macmahoniano" que MacMahon: "epidemiologia é um método de raciocínio sobre a doença, que trata de inferências biológicas derivadas da observação dos fenômenos da doença em grupos populacionais". Cerca de 10 anos depois, o epidemiologista Olli Miettinem iria ratificar e expressar a radicalização dessa tendência, ao definir a epidemiologia como um "agre- gado de princípios de estudo da ocorrência da doença e estados e eventos relacionados, incluindo aqueles de atenção à saúde, no homem"26.

Tem-se já aqui, a partir desta breve recuperação, elementos suficientes para sustentar a proposição de que, ao longo de seu processo de constituição histórica, o risco epidemiológico adquiriu duas características epistemológicas que o colocam na posição paradoxal aqui apontada. De um lado, seu caráter especulativo e substantivamente instrumental o deixam em condições de expandir de forma potencialmente ilimitada a investigação acerca de associações entre eventos de interesse prático para a saúde. Nesse sentido, a busca pelo conhecimento dos aspectos associados a uma referência positiva de saúde poderiam se apoiar fortemente na epidemiologia.

Por outro lado, a rarefação teórica, relacionada ao apoio estratégico das inferências epidemiológicas na positividade biomédica, tornou-a refém da doença ou de eventos relacionados. Não há qualquer referência autônoma positiva que permita à epidemiologia validar conhecimentos acerca de uma configuração sócio-sanitária favorável ou desfavorável à qualidade de vida, para além da indicação das probabilidades de ocorrência ou prevenção de agravos.

Isto posto, a proposta de articular a epidemiologia com as propostas recentes rumo à conceituação positiva de saúde imporá profundas reflexões, que se estendem desde a identificação de impasses metodológicos bastante concretos até questionamentos de ordem mais propriamente filosófica.

\section{Epidemiologia e Saúde: Desafios ao Paradigma do Risco}

Embora já sejam evidentes alguns importantes esforços intelectuais para uma conceituação positiva da saúde ${ }^{27}$, essa discussão ainda não foi consistentemente trazida para o âmbito mais particular da epidemiologia. Nas discussões acerca da promoção da saúde, e mais ainda naquelas 
sobre vigilância à saúde, a epidemiologia tem sido apontada como um instrumento não apenas útil, mas imprescindível mesmo. Contudo, permanecem à margem das discussões as mudanças necessárias para o trânsito teórico para as novas proposições.

Ocorre que, por tudo o que foi discutido acima, é visível que, ao se organizar fundamentalmente em torno às análises de risco, o instrumental epidemiológico tem sua contribuição restrita à prevenção de agravos. Ainda que a epidemiologia contemporânea venha sendo bastante versátil na eleição das variáveis cuja associação estuda, é evidente o predomínio, especialmente entre as variáveis de efeito, dos agravos ou disfunções, isto é, das condições positivamente aferíveis pelas demais ciências biomédicas, já que este é um requisito para seu manuseio e validação em termos de especulação causal ${ }^{28,29}$. Em uma situação em que se busque inquirir epidemiologicamente acerca do que produz saúde, e portanto deva ser promovido, ao invés do que produz doença, e enquanto tal deva ser evitado, será preciso definir o que, e com que fundamentação, deverá ser considerado o efeito saúde.

É possível, ao modo de pura especulação, imaginar que há diversas experiências objetivas de onde se pode extrair variáveis de efeito relacionadas à saúde. Desde a idéia veiculada na famosa definição de saúde como bem estar físico, mental e social até as recentes discussões sobre qualidade de vida, há todo um elenco de condições e situações avaliadas positivamente, entendidas como bens a que os indivíduos podem e devem aspirar para o seu bem viver. Há, porém, duas ordens de questões metodológicas de difícil solução nessa proposição.

A primeira delas diz respeito a essa própria valorização positiva: Quem define o que é o bem viver, ou, dito de outra forma, quem define o efeito saúde? Será possível alcançar nas formulações positivas de saúde o mesmo grau e tipo de consenso que possibilitou a formalização do discurso do risco em torno das doenças infecciosas e consolidado na epidemiologia das doenças crônico-degenerativas?
Apontou-se acima como foi fundamental para o desenvolvimento de uma linguagem formal em epidemiologia o estreitamento das relações entre o raciocínio epidemiológico e a conceituação de agravo emprestada da microbiologia, da virologia, da imunologia, etc. A passagem da epidemiologia das doenças infecciosas para as crônicas degenerativas já apresentou uma série de desafios epistemológicos, uma vez que os critérios de causalidade de Henle-Koch não se aplicavam a estes novos objetos. O caráter multicausal e não unívoco das associações entre exposição e agravo no caso dessas doenças levou a um debate que, estendendo-se por mais de dez anos, acabou por desembocar nos critérios de associação causal de Bradford Hill. Nesse caso, contudo, o controle estatístico da incerteza das inferências, o refinamento das técnicas de análise da probabilidade das associações e, muito especialmente, a definição morfo-funcional dos critérios de agravo, garantindo a verificação da associação, não apenas permitiram a sobrevivência das análises de risco como fizeram delas um dos mais importantes acontecimentos no campo das ciências da saúde na contemporaneidade.

Há que se indagar, contudo, onde se apoiará, no caso desse trânsito ao efeito saúde, a possibilidade de verificação das associações. Há algum substrato positivamente verificável para o efeito saúde? Se a saúde é, por definição, entendida como um bem estar físico, mental e social, não será de caráter extremamente subjetivo e interpretativo a qualificação do efeito saúde? Não será, por outro lado, uma condição complexa, tanto no efeito quanto na exposição, exigindo um movimento de síntese, refratário, portanto, às decomposições analíticas necessárias aos testes de associação?

A segunda ordem de questões metodológicas relacionadas à busca do efeito saúde diz respeito à questão da extensão de suas indagações e inferências. Todo discurso científico formalizado busca, no maior grau possível, a universalidade de seus constructos. Com efeito, em um sistema de linguagem que busca basear sua argumentação e 
verificação em relações necessariamente implicadas entre si, a universalidade não é apenas um ideal, mas uma exigência mesmo. O máximo que se admite aí é a limitação da certeza sobre quão universal é uma proposição ou constatação, limitação esta que só é aceita como provisória e inerentemente ligada à incompletude do conhecimento humano. O impacto pragmático do tipo e grau de incerteza com que se precisa lidar e a existência ou não de outras alternativas menos imprecisas para tratar do mesmo campo de interesses científicos são, em última análise, os critérios que decidirão até que ponto um dado discurso formal será aceito ou não pela comunidade científica.

O que se coloca com a conceituação positiva de saúde é, porém, a assunção ativa de que estaremos tão mais próximos de uma definição precisa de efeito quanto mais nos aproximarmos da totalidade particularizadora da situação física, mental e social dos indivíduos em questão. Ou seja, o rigor necessário à definição das variáveis a serem estudadas varia na relação inversa da sua universalidade. Não se trata de um limite provisório e controlável. Trata-se de uma contradição instalada no cerne da validade proposicional desse discurso.

Esses impasses metodológicos obrigam, como se pode ver, a reflexões que não se restringem apenas ao plano metodológico, mas atingem a própria dimensão epistemológica. Se as análises de risco têm dificuldade de sustentar seu rigor frente à plurivocidade e contingencialidade das categorias relacionadas à especulação causal sobre o efeito saúde, possivelmente esse tipo de investigação precisará abandonar esse modelo heurístico.

Assumindo-se que a definição de saúde é refratária à sua decomposição analítica em elementos de menor complexidade e subjetividade, e que a facticidade dos fenômenos da saúde vincula a validade das proposições a seu respeito a graus elevados de contingência, é forçoso admitir que uma epidemiologia da saúde é uma proposição internamente contraditória. É possível estudar associações entre variáveis que não podem ser clara e distintamente implicadas entre si? É possível atribuir valores quantitativos a variáveis cuja identidade é em tão alto grau dependente das circunstâncias e dos sujeitos que as formulam? Existirá uma "epidemiologia sem números”? Há epidemiologia sem risco?

Se o metodológico remeteu ao epistemológico, este conduz a uma questão puramente filosófica: Deve-se trabalhar a saúde epidemiologicamente?

Esta parece ser a pergunta que deve ser feita diante dos desafios acima colocados. Valores preciosos foram historicamente construindo as proposições de práticas assistenciais centradas na saúde, quais sejam, a politização, democratização, desburocratização, participação, humanização, pluralidade, eqüidade, entre outros. Não faria qualquer sentido abrir mão desses valores em função das dificuldades de manipulálos epidemiologicamente. Isto parece óbvio. O que não parece tão óbvio, mas que seria igualmente absurdo, seria cobrar da epidemiologia uma "correção de rumos", como se o descompasso entre a promoção da saúde e a epidemiologia fosse um "acidente" ou uma insuficiência dessa ciência.

Na verdade, toda a recuperação histórica acima sintetizada quis justamente ressaltar as motivações e escolhas que subjazem qualquer discurso racional, mesmo aqueles com alto grau de formalização, como é o caso do discurso do risco. O que foge ao discurso do risco não é aquilo que lhe escapou, mas aquilo que de alguma forma não lhe diz respeito, não esteve entre as exigências/condições normativas, proposicionais ou expressivas que o conformaram. Por isso, nos balizamentos teórico-filosóficos desta reflexão, a pergunta que cabe fazer neste ponto não é tanto sobre a necessidade de trabalhar a saúde epidemiologicamente, nem tanto sobre a possibilidade de fazê-lo. A pergunta fundamental aqui é sobre o interesse em fazê-lo.

É desejável trabalhar a saúde epidemiologicamente? Da resposta a essa pergunta dependem as conformações futuras tanto dos discursos epidemiológicos quanto das pro- 
postas de promoção da saúde. Tanto uma quanto outra são racionalidades abertas e só o ativo diálogo entre elas, norteado pelas pretensões e exigências de validade de que vão sendo socialmente investidas, poderá definir seus destinos.

\section{Sugestões para os Diálogos entre Epidemiologia e Promoção da Saúde}

Entendido nos mesmo moldes em que, seguindo Habermas, qualquer discurso racional pode ser compreendido, o desafio conceitual da promoção da saúde impõe pensar as condições de validade normativa, expressiva e proposicional dos discursos que aspiram orientar esta prática. Das reflexões acima pode-se sugerir aqui algumas possíveis sugestões de alternativas para tal construção.

Veja-se, em primeiro lugar, o tipo de desafio que se coloca quando se busca expressar uma objetividade que, como foi visto, mostra-se bastante refratária à positivação e manipulação por discursos formalizados. É com cautela que se deve atentar para tal refratariedade, para as "mensagens" que através dela nos mandamos acerca da facticidade de nossa existência enquanto seres vivos, produtores de discursos capazes de interferir sobre as condições que regulam nossa existência material.

Seguindo Canguilhem ${ }^{30}$, é possível aceitar que nossos discursos científicos são como "dispositivos" vitais que buscam manter uma organização aberta, uma permanência material que se dá pela capacidade de perceber e responder ao imponderável que é nosso meio-socialmente biológico, biologicamente social. Somos seres criadores e, até por isso mesmo, vivemos num meio em constante mutação. A mudança é nossa marca de origem, condição de possibilidade da nossa existência e elemento necessariamente incluído em nossa permanência. Ora, por isso mesmo, toda a normatividade que criamos por intermédio da razão, toda a adequação que fazemos em nós e nosso meio para seguir vivendo, e para viver melhor, jamais pode ser concebida a priori, de modo unívoco e permanente. A vida humana só percebe algo de que precisa quando de alguma forma esse algo se lhe apresenta como carecimento. Tal parece ser o caso da saúde.

É esta percepção que leva Canguilhem a afirmar que, embora epistemologicamente o fisiológico, o funcionamento normal da economia orgânica humana, dê base à enunciação científica do fenômeno patológico, este antecede àquele ontologicamente. O patológico precede o normal, e o define. Os obstáculos à vida humana é que a tornam a si mesma inteligível em suas exigências e preferências. Nesse sentido, cabe perguntar até que ponto é desejável, racional, prático buscar conceituar positivamente a saúde? Será a recusa em organizar as práticas de saúde em torno do tratamento de patologias ou prevenção de agravos dependente mesmo de uma conceituação positiva de saúde?

A resposta talvez não esteja em um extremo ou noutro: conceituação de saúde ou iatrocentrismo. Mas também é certo que não é possível, ao menos não é desejável, que todo o enorme arsenal científico e tecnológico disponível nesse início de século XXI seja posto, como tem sido, de forma tão pouco criativa a serviço de corrigir ou prevenir doença. A construção da saúde possivelmente precisará sempre dos problemas, obstáculos, dos agravos, para que possa se aperceber de seus próprios interesses e meios de alcançá-los, mas essa apercepção poderá ser favorecida e potencializada se tais problemas e obstáculos forem tratados como $o b$ jetos contrafáticos. Isto é, não é preciso abandonar a conceituação das doenças para se produzir conhecimento sobre saúde, mas certamente é preciso interpretar e tematizar ativamente que valores vitais obstaculizados as patologias, tais como as conceituamos, estão revelando.

Se considerada como um fato em si mesma, a doença se absolutiza, essencializa e, enquanto tal, permanece reproduzindo respostas em uma mesma direção e sentido, constrangendo os potenciais criativos da vida, inibindo a manifestação de formas mais 
ricas e ativas de saúde. Sob uma compreensão contrafática, a doença obriga a pensar sobre aquilo que, estando de um modo, poderia estar de outro; obriga a refletir sobre outros modos em que a vida poderia estar correndo, motivando e organizando mudanças, buscando enriquecer suas qualidades.

Uma conseqüente assunção do caráter contrafático do objeto doença conduz à necessidade de uma segunda sugestão. A transformação do tipo de resposta a ser dada à positividade do agravo: de uma tentativa sempre voltada para sua supressão ou prevenção à sua incorporação em um movimento interpretativo, que faça emergir e criticar os conteúdos valorativos, normativos, que estão na base da sua positividade. Este movimento implica um ativo trânsito interdisciplinar. Senão, de que forma identificar, interpretar e validar, de modo autêntico, verdadeiro e legítimo, as diferentes dimensões da vida negadas pelos agravos e adoecimentos? A fusão dos horizontes discursivos das diversas disciplinas científicas requer não o abandono de um discurso em prol de outro, mas a criação de categorias que expressem os novos contornos que adquirem seus constructos a partir das luzes que sobre ele projetam os discursos de outras disciplinas.

Assim é que não faz sentido reclamar uma epidemiologia sem números ou sem risco, mas há que se buscar categorias que permitam fazer dialogar os seus achados com outras construções conceituais. Tais categorias, ao oferecer a re-leituras transdisciplinares a positividade que a epidemiologia confere aos agravos pode potencializar a contribuição desta ciência ao desafio de promover saúde*.

Claro que essa transdisciplinaridade não se constrói da noite para o dia, nem por decreto, mas implica arranjos técnicos e institucionais que permitam um efetivo trân- sito de sujeitos entre diferentes áreas e grupos de produção científica ${ }^{32}$. Este trânsito, por seu lado, encontra sérios obstáculos nas rígidas e poderosas fronteiras disciplinares, que delimitam não apenas áreas de competência científica, mas sólidos interesses e poderes socialmente consusbstanciados e que não se deixam remover ingenuamente, sem resistência ${ }^{33}$.

Há, portanto, significativos esforços a serem empreendidos no plano político para que epidemiologia e promoção da saúde possam efetivamente dialogar, resumidos na necessidade de se dissolver a "feudalização" das ciências e suas instituições. Quanto a isso, não parece haver "solvente" mais eficaz que o poder da solução, isto é, a autoridade e legitimidade que advêm da capacidade para se oferecer respostas razoáveis para situações que obstaculizam o bom curso da vida no seu cotidiano. Na capacidade de identificar problemas práticos que agreguem o maior número possível de interesses sociais e de organizar em torno desses problemas, e não de áreas abstratas de expertise, esforços transdisciplinares e intersetoriais de várias ordens (caráter público e privado; diferentes áreas de competência; pesquisa e serviços; etc), encontra-se, com efeito, um irresistível impulso à efetividade e legitimidade de diálogos transdisciplinares. A cada disciplina a importância relativa ao que tem de efetivo a dizer sobre o problema prático em questão.

Temos todas as razões para ser otimistas quanto a estes rearranjos no campo da saúde, uma vez que as propostas de promoção da saúde, como também as de vigilância da saúde, por força do caráter politizado, democratizado e regionalizado que querem imprimir à organização das práticas assistenciais, constróem um novo e muito favorável cenário para que prevaleça o poder da solução, o qual, se estivermos corretos, será essencial para sua própria viabilidade.

\footnotetext{
* O autor tem procurado, por meio do conceito de vulnerabilidade, promover o diálogo entre a epidemiologia e outras disciplinas de interesse para a saúde. Tal discussão não cabe nos limites deste artigo, recomendando-se aos interessados remeter-se aos trabalhos sobre o tema ${ }^{31}$.
} 


\section{Referências}

1. Minayo MCS, Hartz ZMA, Buss PM. Qualidade de vida e saúde: um debate necessário. Ciênc \& Saúde Colet 2000; 5: 7-18.

2. Teixeira CF, Paim JS, Vilasbôas AL. SUS, modelos assistenciais e vigilância da saúde. Informe Epidemiológico do SUS 1998; VII(2): 7-28.

3. Souza MFM, Kalichman AO. Vigilância à saúde: epidemiologia, serviços e qualidade de vida. In Rouquayrol MZ. Epidemiologia e saúde. Rio de Janeiro: Medsi; 1993, p. 467-76.

4. Czeresnia D. The concept of health and the difference between prevention and promotion. Cad Saúde Pública 1999; 15: 701-9.

5. Buss PM. Promoção da saúde e qualidade de vida. Ciênc \& Saúde Colet 2000; 5: 163-77.

6. Foucault M. A arqueologia do saber. Rio de Janeiro: Forense-Universitária; 1987.

7. Costa NCA. O conhecimento científico. São Paulo: Discurso Editorial; 1997.

8. Granger GG. Por um conhecimento filosófico. Campinas: Papirus; 1989.

9. Gadamer HG. Verdad y método. Salamanca: Sígueme; 1991.

10. Habermas J. Teoría de la acción comunicativa. Madrid: Taurus; 1998.

11. Ayres JRCM. Sobre o risco. São Paulo: Hucitec; 1997.

12. Ackerknecht EA. Hygiene in France, 1815-1848. Bull Hist Med 1948; 22: 562-93.

13. Canguilhem G. O normal e o patológico. Rio de Janeiro: Forense-Universitária; 1982.

14. Ayres JRCM. Epidemiologia e emancipação. São Paulo: Hucitec; 1995.

15. França Júnior I. A antropometria como prática social de saúde: uma abordagem histórica [dissertação de mestrado]. São Paulo: Faculdade de Medicina da USP; 1993.

16. Vandenbroucke JP, Rodda HME, Beukers H. Who made John Snow a hero? Am J Epidemiol 1991; 133: 967-73.

17. Barreto ML. A epidemiologia, sua história e crises: notas para pensar o futuro. In: Costa DC. Epidemiologia: teoria e objeto. São Paulo: Hucitec; 1999.
18. Fee E. Disease and discovery: a history of the Johns Hopkins School of Hygiene and Public Health, 19161939. Baltimore: The Johns Hopkins University Press; 1987.

19. Pettenkofer M. The value of health to a city. II. Bull Hist Med 1942; 11: 593-613.

20. Hamer WH. Epidemic diseases in England: the evidence of variability and of persistence of type. Lancet 1906; II: 569-74, 655-62, 733-9.

21. Frost WH. Some conceptions of epidemics in general. Am J Epidemiol 1976; 103: 141-51.

22. MacMahon B. Profile: Department of Epidemiology. Harvard Public Health Alumni Bulletin 1959; June: 810 .

23. Frost WH. Epidemiology. In: Maxcy KF. Papers of Wade Hampton Frost: a contribution to epidemiological method. New York: Commonwealth Fund; 1941. p. 493-542.

24. MacMahon B, Pugh T. Princípios y métodos de epidemiología. México: La Prensa Médica Mexicana; 1975.

25. Lilienfeld D. Definitions of epidemiology. Am J Epidemiol 1978; 107: 87-90.

26. Miettinen OS. Theorethical epidemiology: principles of occurence research in medicine. Nova York: John Wiley \& Sons; 1985.

27. Almeida Filho N. For a general theory of health: preliminary epistemological and anthropological notes. Cad Saúde Pública 2001; 17: 753-99.

28. Hill AB. The environment and disease: association or causation? Proc R Soc Med 1965; 58: 295-300.

29. Rothman K. Modern epidemiology. Boston: Little, Brown \& Company; 1986.

30. Canguilhem G. O normal e o patológico. Rio de Janeiro: Forense-Universitária; 1982.

31. Ayres JRCM, França Júnior I, Calazans, GJ, Saletti Filho HC. Vulnerabilidade e prevenção em tempos de aids. In: Barbosa RM, Parker RG. Sexualidades pelo avesso: direitos, identidades e poder. Rio de Janeiro: IMS/ UERJ, Editora 34; 1999. p. 49-72.

32. Almeida Filho N. Transdisciplinaridade e saúde coletiva. Ciênc \& Saúde Colet 1997; 2(1/2): 5-20.

33. Ayres JRCM. Deve-se definir transdisciplinaridade? Ciênc \& Saúde Colet 1997; 2(1/2): 36-8. 